\title{
Review of Research on Female Physical and Psychological Aggression
}

\author{
Ali Edalati \\ Faculty of Human Ecology, Universiti Putra Malaysia \\ 43400 Serdang, Selangor, Malaysia \\ Tel: 60-1-2279-3206_E-mail: alisq2008@yahoo.com \\ Ma'rof Redzuan (Corespondent authour) \\ Faculty of Human Ecology, Universiti Putra Malaysia \\ 43400 Serdang, Selangor, Malaysia \\ E-mail: marof@putra.upm.edu.my \\ Mariani Mansor \\ Faculty of Human Ecology, Universiti Putra Malaysia \\ 43400 Serdang, Selangor, Malaysia \\ E-mail: mariani@putra.upm.edu.my \\ Mansor Abu Talib \\ Faculty of Human Ecology, Universiti Putra Malaysia \\ 43400 Serdang, Selangor, Malaysia \\ E-mail: mansorat@putra.upm.edu.my
}

\begin{abstract}
Several studies conducted on female aggression (physical and psychological) are the primary concern of the review done in this paper. This article contains three parts - the first part focuses on the findings which show that the rate of aggression for male and female are equal, while the second part focuses on the research that reveal the rate of physical aggression is higher in women than men. The third part concerns on studies which have shown higher level of psychological aggression in women compared to men. According to the existing literatures, the rate of female aggression is equal to those of men, and in some studies, the rates of physical and psychological aggression among women are found to be higher than among men. Thus, it is concluded that the rate of women aggression is not lower than men, but it is either equal to or higher than men.
\end{abstract}

Keywords: Women aggression, Female aggression, Physical aggression, Psychological aggression

\section{Introduction}

It is important to note that no evidence has shown that women must be less hostile than men in order to get into aggressive behaviour. Therefore, it is obviously not practical to merely indicate or even conclude that women are less aggressive than men, as they may use other means and ways in order to behave aggressively. Based on related studies conducted and articles written on family aggression, it is concluded that most of the research has focused on men aggression, while only a few studies have placed emphasis on aggression among women. This could be due to some reasons which include the attitude towards the fact that aggression is only committed by men, and most victims of aggression are women, as well as because of the fact that women are physically weaker and thus assumed as incapable to be behave aggressively. The second reason is related to the perception where most people believe that this issue of female aggression is a taboo especially in the third world. Despite all the researches that have been conducted on family (domestic) aggression, the problem related to this aggression still 
exists, and family members suffer due to this problem. Moreover, the negative effects of family aggression on the children and the society are undeniable, and it has also marked detrimental consequences for both victims and aggressors. Kanoy, Ulku-Sreiner, Cox, and Burchinal (2003) stated that the negative effects of family aggression on children and society are undeniable, and they have marked detrimental consequences for both victims and aggressors. This consequently leads to the requirement for more research to be carried out on both family members, particularly the parents.

As compared to male aggression, only a few studies have been carried out on female aggression. Nonetheless, researchers have recently shown an increased interest in family aggression, and therefore have heightened the need to investigate this phenomenon across the world's most vulnerable societies. In general, the refusal and ignorance towards wives' aggression against their husbands have continued in the different parts of the world. According to Straus (2006), wives' (or women) aggression is a newly founded issue and it is as important as the problem pertaining to husbands' aggression, asserting that the most unreported crime is wives' aggression. Moreover, it is important to highlight that aggression among women has been generally ignored by societies and governments all over the world for many years, particularly in developing countries. Nevertheless, it has gained attention among research institutions and more budgets are allocated to study this matter. Moreover, the accessibility of the scientific resources in some countries has assisted the researchers to present a clearer picture of this phenomenon.

\section{The Concept and Factors of Aggression}

Taylor, Paplau and Sears (2006) define aggression as any action that is intended to hurt others. Aggression is related to the intentional infliction of some form of harm on other Meanwhile, Baron and Byrne (2000) define aggression as a behaviour directed toward the goal of harming another living being who is motivated to avoid such treatment. Meanwhile, the concept of female aggression is generally referred to the wives' aggressive behaviour towards their husbands. It is considered as part of as intimate partner violence (IPV). Cunradi, Bersamin and Ames (2009) termed this concept as female-to-male partner violence (FMPV) in which referred to the act of wives in hurting or harming their partners (husbands) intentionally.

There are several theories that explain the roots of human aggression in general. Instinct theories suggest that aggression seems largely from innate urges and tendencies. Konrad Lorenz and Sigmund Freud were among of the proponents of instinct theories. However, social psychologists reject this idea, but they do recognise the potential role of biological factors in human aggression. On the other hand, drive theories suggest that aggression seems from external elicited drives to harm or injure others. The frustration-aggression hypothesis is the most famous example of such theories. This hypothesis suggests that frustration is a very powerful determinant of aggression. Frustration is an emotion in which generally resulted from not getting what one wants (or what one would expect). However, there are several other determinants of aggression besides frustration, such as provocation, media violence and heightened arousal (such as anger and sexual arousal), personality traits (particularly Type A personality) and other types of personality disorders (such as anti-social personality and narcissism). There are also situational determinants of aggression such as high temperatures and consumption of alcohol and drug.

\section{Women and Men are Equal in the Rate of Aggression (Physical and Psychological)}

There are a quite number of researches related to the engagement of men and women in intimate partner violence (IPV) within their relationship (see Archer, 2000). Aggression between spouses has been painfully reported by different sources. These accounts have led to the recognition of the fact that family or domestic aggression is a common phenomenon in today's modern society, in which people may be physically or psychologically assaulted, beaten up, slapped, or even killed in their own homes. This section attempts to highlight several studies related to rate of aggression of women and men.

In their two studies, Katz, Kuffel and Coblentz (2002) reported that there were dating men and women experiencing violence at comparable levels. The studies revealed that men have experienced more frequent moderate violence compared to women. From a sample of 183 women and 103 men in the first study, 55\% of the women had reported no case of violence with their partners, while $50 \%$ of the men only had non-violent mates. Meanwhile, it is reported that from 78 women and 45 men who were eligible for the second study, $73 \%$ of the women had non-violent partners. This figure was reported against the $58 \%$ of men who had reported no violence from their female mates.

George (2003) carried out an analysis on female initiated aggression and reported some historical as well as empirical case evidences to prove the reality of "battered husband syndrome." However, this particular review was re-confirmed by other researchers, such as Felson (2006) who reported that while men were eight times 
more likely to commit overall violence than women, there was gender equality in partner violence.

Recently, Dutton (2007) conducted a similar study on female intimate partner violence and developmental trajectories of abusive families. The researcher found that female violence towards intimate male partners was just as severe as and possessed similar consequences as that of the male violence towards women. This report supports the mixed results as the findings in relation to this issue are rather mixed across the available research literature. For instance, across a sample of 414 students, from whom 189 men and 225 women were drawn from on the CTS2, Cercone, Beach and Arias (2005) reported that male and female subjects were equally committing acts of minor violence in intimate dating relationships. Nevertheless, it was also found that women were twice more likely, as compared to men, to commit severe acts of violence.

Meanwhile, Kessler, Molnar, Feurer and Appelbaum (2001) carried out a wide scope study using a sample of 3,537 subjects (with 1738 men and 1799 women) drawn from the National co-morbidity survey, i.e. a nationally representative survey conducted between 1990 and 1992. The participants were either married couples or were cohabitating men or women between the ages of 15 and 54 year old. These subjects were requested to fill the CTS. The findings of the present study revealed that about $17.4 \%$ of the women and $18.4 \%$ of the men reported that they were victims of minor physical violence committed by their current partners.

Among other comprehensive researches, Brown (2004) summarized the available data on partner violence derived from the 1999 Canadian General Social Survey (GSS), which was carried out based on a representative sample of 25,876 individuals or respondents. In a period of one year to the research period, an estimated $3 \%$ of Canadian women and $2 \%$ of Canadian men were found and reported to experience violence from their partners. The report was continued for the next 5 year's period, i.e. from 1995-1999, in which an estimated $8 \%$ of Canadian women and 7\% of Canadian men were found to report violence from their partners. The available police and legal responses to domestic violence in Edmonton, Canada was reviewed by the researcher, and Brown concluded that men who were engaged in disputes with their partners were disadvantaged by the police or the entertainers, and that they were also treated less favourably by them. In an ethnically diverse sample, Prospero (2007) collected 27\% Hispanic, 18\% African-American, 24\% Asian, and 30\% White from a total of 573 university students (consisting of 241 males, 332 females) and discovered no significant differences between the two groups of respondents, and genders, on abusing their mates.

Hamel (2005) carried out a study and reviewed the most trustworthy and empirically sound research, and found that men and women are physically and psychologically mistreating each other at the same rates. The focus was placed on the psychological aspects of aggression in yet another research comprising of a sample of 236 young people. From this sample, $48 \%$ were married, $52 \%$ were dating, while $56 \%$ were women, and $44 \%$ were men. These respondents were requested to fill in the questionnaires pertaining to their hostility towards their partners. Based on the findings of the study, it was concluded that "couples who are living together have higher level of hostility than dating couples, and that woman in both situations show a higher level of hostility towards their partners than men."

\section{Higher Physical Aggression in Women Compared to in Men}

Jenkins and Aube Jenkins (2002) stated that women, in comparison to men, are in fact more aggressive in some conditions, and thus more likely to kick, hit or physically assault their husbands. Meanwhile, there is a controversy in the intimate partner violence (IPV) related to the rates and consequences of women's use of aggression against the men they love.

Among other, the distribution of physical aggression was noted by Swart, Stevens Ricardo (2002). The study made use of 928 students, with 494 females, 424 males, who were selected from seven schools in South Africa. These students were investigated using a CTS2. The study revealed that $35.3 \%$ of the males and $43.5 \%$ of the females reported committing physical violence against their partners within a 12 month's period prior to the study.

Straus (2008) adopted a sample of university student from 68 countries in another study. For this purpose, the CTS2 was employed. The findings showed that nearly one third of the students had assaulted their dating partners within twelve month prior to the investigation. Furthermore, the results also indicated that mutual aggression was indicated as a reason for almost $68.6 \%$ of physical violence, while violence was found to be initiated by women and this contributed to about $21.4 \%$ of the time, and $9.9 \%$ of violence was reported to be initiated by men at that time.

In a cross-sectional study conducted by Graham, Plant, and Plant (2004), a sample of 2027 subjects were used. The sample consisted of 1052 women and 975 men, Both groups were interviewed in this research to identify for 
their experience of partner aggression. The findings revealed that $16 \%$ of the women were physically aggressive towards their male mates within a period of two years as reported to the interviewers. As for the male participants, only $13 \%$ had experienced some physical aggressions towards their female partners.

Meanwhile in another study by Shook, Gerrity, Jurich and Segrist (2000), the CTS measure was used for a total of 572 students (395 girls, and 177 boys) and it led to the findings revealing that girls were more consistent than boys, with $23.5 \%$ vs. $13.0 \%$, in taking the responsibility that they have been using physical force against their mates. These findings were confirmed by Ridley and Feldman (2003) who conducted a study on 153 women using the Abusive Behaviour Inventory. The findings gathered in the study showed that $67.3 \%$ of the women had committed at least one of the violent behaviours in the past year. However, majority of the observed and reported violent comprised of mainly pushing, shoving, holding down (45.1\%) and slapping, hitting, biting (41.2\%).

In a longitudinal study by Fergusson, Horwood and Ridder (2005), the scope of the extent of domestic violence experience was examined. Their study used a sample of 828 subject, with 437 women, and 391 men. They were mostly young adults aged 25 years old. The respondents were chosen for a long-term longitudinal study and they were requested to take the CTS2. The findings indicated that there were more men than women exposed to severe domestic violence. Furthermore, it was also discovered that mild and moderate rates of violence were equal for men and women. The study also showed that more than $39.4 \%$ of the women and around $30.9 \%$ of the men reported violence scores of 3 or higher. Nevertheless, in terms of partner's initiation of assaults, study showed that about $34 \%$ of the women and $12 \%$ of men reported to have initiated physical assaults on their partners.

On the contrary to these results, Archer (2002) found that women were more likely to throw things at their partners compared to men. Giving some instances of possible reactions, he further indicated that slapping, kicking, biting, punching and hitting with the use of object(s) are rather common. On the other hand, he revealed that men were more likely to strangle, choke, or beat up their partners than women did.

Some other researchers who have analyzed the available research reports are Mallory, McCloskey, Griggsby and Gardner (2003) in order to present a collective account of the issue of aggression (female and wife) in a review research which studies on the use of violence in intimate relationships among women. Based on this, they presented a cumulative account of the issue, including a number of studies which present an account of the increased arrests of women over the reported domestic disputes.

\section{Higher Psychological Aggression in Women Compared in to Men}

A number of studies have focused on the psychological aspect of aggression. For instance, sample comprising of 453 couples, who were cohabiting and had a child, were questioned with the use of the CTS2 and a scale to assess their precipitants for aggression by their partners. In other hand, O'Leary and Slep (2006) discovered that women were more likely than men to commit both mild aggressions, with around $23.8 \%$ as compared to $33.8 \%$ and $8.4 \%$ (compared to vs. $11.5 \%$ ) for severe aggression. This study indicated that men were more likely to claim partner physical aggression once reporting their experience of physical aggression as compared to women, whereas the physical aggression of women was more probably to be caused by (or as a response to) their partner's psychological aggression. Therefore, it was concluded that women were the ones who escalated aggression and this was followed by their attempts to defend violently.

Another technique wives use in their fights is psychological aggression. According to Shook, Gerrity, Jurich, and Segrist (2000), this particular aggression technique is more common than physical aggression. In his research and treatment in the area of couple violence, Dutton (2006) offered much insight which was specifically addressed to therapists and policy makers in relation to family conflicts. He further concluded that men were as likely as women to be victims and that both suffered similar physical and psychological outcomes of spousal conflict. Meanwhile, Harned (2001) argued that females were more likely than men to perpetrate psychological aggression.

A study on aggression against children was conducted by Chalabi and Rasoulzadeh (2002) on 300 urban families in Tehran, using the measurement method. The finding of their study revealed the rate of mothers' aggression against children was generally higher than fathers. Moreover, psychological aggression and neglect abuse were found to be of a greater portion as compared to physical aggression.

Females were found to be more likely to perpetrate psychological aggression than males (Harned, 2001). In his study, the collected data showed that men demonstrated a greater likelihood of being victimized by psychological aggression than their female counterpart. In addition, the reports by the participants' seemed to suggest that women could be more psychologically aggressive than men. As well as in their study, Perry and 
Fromuth (2005) completed the Conflict Tactic Scale-Revised and found that female reported a greater likelihood of psychologically aggression against their male partner than the males. Moreover, women's sum and quantity perpetrations of psychological aggression were found to be higher than the sums and quantity of victimization by psychological aggression.

The Conflict Tactics Scale-Revised was employed by Hines and Saudino (2003) in their study which found that $86 \%$ of the women and $82 \%$ of the men informed perpetration of psychological aggression in their partner relations. The samples comprised of college students and based on the findings of their study, they defined psychological aggression as swearing, shouting and yelling at partner. Meanwhile, women were found to report psychological aggression more than their male partners (Swan \& Snow, 2002). The Conflict Tactics Scale-Revised was used in their study and based on which they defined psychological aggression as swearing or insulting at their partner.

According to Crick and Grotpeter (1995), due to the fundamental differences between their social goals, girls usually display their aggressive behaviour through covert acts, while boys through their overt, physical acts. In other words, they develop other means to accomplish their goals as they are physically weaker. Thus, in comparison to men, women may probably opt for and utilise different means or strategies in comparison to men. In addition, human beings are known to have non-physical abilities, i.e. their aggression is obviously different from that of the animals. In their research, Shook, Gerrity, Jurich and Segrist (2000) found that $83 \%$ of the females and $80 \%$ of the males reported perpetration of psychological aggression against their intimate partners during the previous year. Interestingly, the researchers also found that the rates of psychological aggression as higher for women than men.

Moreover, women have been shown to get involved with aggressive behaviour toward their partners as frequently as men (Straus, 2006). Meanwhile, Stets (1991) indicated that psychological aggression could be predicted by the increased interpersonal control, showing that both men and women were likely to commit psychological aggressions in their attempts to get their partner to behave according to their desire. The findings showed that women were the only perpetrator of aggression in $22.7 \%$ of the aggression and violence reported in the families, while the husbands were revealed as the solitary aggressors in $27.7 \%$ of the incidences. However, the results did not show any differences between the male and female reports on psychological aggression towards their partners. In their study, Perry and Fromuth (2005) utilised the Conflict Tactic Scale-Revised which was completed by both partners; this gave the frequencies of both received and performed psychological aggression, Similar to the findings of other researchers. The female self-reported a greater likelihood of psychological aggression against their male partners than the males. In total, women's amount perpetrations of psychological aggression was found to be greater than the sums of victimization by psychological.

Therefore 1,635 couples were requested to complete the CTS in the study by Caetano, Schafter, Field, and Nelson (2002). The study yielded that the agreement in relation to mutual partner violence was about $40 \%$. In addition, across the three ethnic groups, wives were reported to commit more partner violence compared to their spouses. This finding was regarded as providing support to the race-free and ethnicity-free profile of violence. Nevertheless, the findings gathered were observed to be in conformity with other available studies. Across the other studies, the same distribution which carried more or less similarities was also observed. Using the CTS in their experimental study on 120 students (61 males and 59 females), Simonelli, Mullis, Elliot and Pierce (2002) found that both genders (i.e. $10 \%$ of males and $33 \%$ of females) had committed at least one type of physical aggressive behaviours. In addition, $18 \%$ males and $15 \%$ females were also found to have been under physical aggression from their partners.

In an examination of the literature, the study by Lewis and Fremouw (2001) cited that many evidences showed that females had initiated more violence than males. However, the researcher conducting the present study believes that such findings still needed to be confirmed using a meta-analysis of either descriptive researches, or surveys which have been conducted so far, particularly in relation to the role and nature of female aggression which is obviously found in the reviewed literature, except for a few cases. For instance, in a meta-analysis of sex differences in physical aggression, Archer (2000) indicated that women were found to be more likely (than men) to use one or more acts of physical aggression and thus, use these acts more frequently as well.

\section{Conclusion}

The review of several studies has shown that female aggression is an important worldwide problem, and it exists in all countries. Unfortunately till the present day, little attention has been given to fully understand aggression among women as the issue has been shrouded by the focusing on aggression among men. A good understanding of the problem occurring inside family can only be achieved if there are more research done to study both men 
and women behaviour and the problem around the two different genders. In conclusion, without ample studies on women and their aggression, our picture of family and the problems related to it will not be clear.

\section{References}

Archer, J. (2000). Sex differences in aggression between heterosexual partners: A meta-analytic review. Psychological Bulletin, 126(5), 651-680.

Archer, J. (2002). Sex differences in physically aggressive acts between heterosexual partners: A meta-analytic review. Aggression and Violent Behaviour, 213-351.

Baron, R. A \& Byrne, D. (2000). Social Psychology, (9 ${ }^{\text {th }}$ Edition). Boston: Allyn and Bacon.

Brown, G. (2004). Gender as a factor in the response of the law-enforcement system to violence against partners. Sexuality and Culture, 8(3-4), 3-139.

Caetano, R., Schafter, J., Field, C., \& Nelson, S. M. (2002). Agreement on reports of intimate partner violence among white, Black, and Hispanic couples in the United States. Journal of Interpersonal Violence, 17(1308-1322).

Cercone, J. J., Beach, S. R. H., \& Arias, I. (2005). Gender Symmetry in Dating Intimate Partner Violence: Does Behavior Imply Similar Constructs? Violence and Victims, 20(2), 207-218.

Chalabi, M., \& Rasoulzadeh, S. (2002). Influence of family order and conflict on violence against children. Iran sociology Journal, (4th ed). 2, 26-54.

Crick, N. R., \& Grotpeter, J. K. (1995). Relational aggression, Gender and Social-Psychological Adjustment. Child Development, 66, 710-722.

Cunradi, C. B., Bersamin, M. \& Ames, G. (2009). Agreement on intimate partner violence among a sample of blue-collar couples. Journal of Interpersonal Violence, 24, 551-568.

Dutton, D. G. (2006). Rethinking Domestic Violence. Vancouver: UBC Press.

Dutton, D. G. (2007). Female intimate partner violence and developmental trajectories of abusive families. International Journal of Men's Health, 6, 54-71.

Felson, R. B. (2006). Is violence against women about women or about violence? Contexts, 5, 21-25.

Fergusson, D. M., Horwood, L. J., \& Ridder, E. M. (2005). Partner violence and mental health outcomes in a New Zealand birth cohort. Journal of Marriage and Family, 67, 1103-1119.

George, M. J. (2003). Invisible touch. Aggression \& Violent Behaviour, 8, 23-60.

Hamel, J. (2005). Gender Inclusive Treatment of Intimate Partner Abuse. New York: Springer.

Harned, M. S. (2001). Abused women or abused men? An examination of the context and outcomes of dating violence. Violence and Victims, 16(269-285).

Hines, D. A., \& Saudino, K. J. (2003). Gender differences in psychological, physical, and sexual aggression among college students using the Revised Conflict Tactics Scales. Violence and Victims, 18, 197-218.

Jenkins, S. S., \& Aube, J. (2002). Gender differences and gender related constructs in dating aggression. Personality and Social Psychology Bulletin, 28, 1106-1118.

Kanoy, K., Ulku-Sreiner, B., Cox, M., \& Burchinal, M. (2003). Marital relationship and individual psychological characteristics that predict physical punishment of children. Family Psychology, 17(1), 20-28.

Katz, J., Kuffel, S. W., \& Coblentz, A. (2002). Are there gender differences in sustaining dating violence? An examination of frequency, severity, and relationship satisfaction. Journal of Family Violence, 17, $247-271$.

Kessler, R. C., Molnar, B. E., Feurer, I. D., \& Appelbaum, M. (2001). Patterns and mental health predictors of domestic violence in the United States. International Journal of Law and Psychiatry, 24, 487-507.

Lewis, S. F., \& Fremouw, W. (2001). Dating violence: A critical review of the literature. Clinical Psychology Review, 21(1), 105-127.

Mallory, K. A., McCloskey, K. A., Griggsby, N., \& Gardner, D. (2003). Women's use of violence within intimate relationships. Journal of Aggression, Maltreatment \& Trauma, 6(2), 37-59.

O'Leary, S. G., \& Slep, A. M. S. (2006). Precipitants of Partner Aggression. Journal of Family Psychology, 20, 344-347.

Perry, A. R., \& Fromuth, M. E. (2005). Courtship Violence Using Couple Data. Journal of Interpersonal 
Violence, 20(9), 1078-1095.

Prospero, M. (2007). Mental health symptoms among female and male victims of partner violence. American Journal of Men's Health, 1, 269-277.

Shook, N. J., Gerrity, D. A., Jurich, J., \& Segrist, A. E. (2000). Courtship violence among college students: A comparison of verbally and physically abusive couples. Journal of Family Violence, 15, 1-22.

Simonelli, C. J., Mullis, T., Elliot, A. N., \& Pierce, T. W. (2002). Abuse by siblings and subsequent experiences of violence within the dating relationship. Journal of Interpersonal Violence, 17, 103-121.

Stets, J. E. (1991). Psychological aggression in dating relationships. Journal of Family Violence, 6, 97-114.

Straus, M. A. (2006). Future research on gender symmetry in physical assaults on partners. Violence against Women, 12, 1086-1097.

Straus, M. A. (2008). Dominance and symmetry in partner violence by male and female university students in 32 nations. Children and Youth Services Review, 30, 252-275.

Swan, S. C., \& Snow, D. L. (2002). A typology of women's use of violence in intimate relationships. Violence against Women, 8(3), 286-319.

Swart, L. A., Stevens, M. S. G., \& Ricardo, I. (2002). Violence in adolescents' romantic relationships: findings from a survey amongst school-going youth in a South African community. Journal of Adolescence, 25(385-395). 